\title{
Beyond the First Wave: Consequences of COVID-19 on High-Risk Infants and Families
}

\author{
Monica E. Lemmon, MD ${ }^{1,2}$ Ira Chapman, MD ${ }^{3}$ William Malcolm, MD ${ }^{2}$ Kelli Kelley \\ Richard J. Shaw, MD ${ }^{5}$ Angelo Milazzo, MD $\quad$ C. Michael Cotten, MD ${ }^{2}$ Susan R. Hintz, MD
}

${ }^{1}$ Department of Population Health Sciences, Duke University School of Medicine, Durham, North Carolina

Address for correspondence Monica E. Lemmon, MD, Department of

2 Department of Pediatrics, Duke University School of Medicine, Pediatrics and Population Health Sciences, Duke University School of Durham, North Carolina

${ }^{3}$ Division of Neonatology, Department of Pediatrics, Emory

University School of Medicine, Atlanta, Georgia

${ }^{4}$ Hand to Hold, Austin, Texas

${ }^{5}$ Department of Psychiatry and Behavioral Sciences, Stanford

University School of Medicine, Palo Alto, California

${ }^{6}$ Department of Pediatrics, Stanford University School of Medicine,

Palo Alto, California

Am J Perinatol 2020;37:1283-1288.

\begin{abstract}
Keywords

- family-centered care

- communication

- telemedicine

- parent mental health

The novel coronavirus disease 2019 (COVID-19) pandemic is affecting care for high-risk newborns in ways that will likely be sustained beyond the initial pandemic response. These novel challenges present an urgent imperative to understand how COVID-19 impacts parent, family, and infant outcomes. We highlight three areas that warrant targeted attention: (1) inpatient care: visitation policies, developmental care, and communication practices; (2) outpatient care: high-risk infant follow-up and early intervention programs; and (3) parent psychosocial distress: mental health, social support, and financial toxicity. Changes to care delivery in these areas provide an opportunity to identify and implement novel strategies to provide family-centered care during COVID-19 and beyond.
\end{abstract}

\section{Key Points}

- The COVID-19 pandemic is influencing care delivery for high-risk newborns and their families.

- Rapid changes to care delivery are likely to be sustained beyond the initial pandemic response.

- We have an urgent imperative to understand how COVID-19 impacts infant, parent, and family outcomes.

The novel coronavirus disease 2019 (COVID-19) has introduced profound changes to health care delivery across the world. Strategies to mitigate spread have varied by unit, region, and country. Neonatal intensive care units (NICUs) have worked to balance safety with providing family-centered care by implementing new visitation policies, changing the format of team and bedside communication, and embracing opportunities to connect virtually with patients and families.

To date, COVID-19 research has largely concentrated on the adult population and has focused on the epidemiology of the disease, improving testing methodologies, potential therapies, and vaccine development. Research specific to neonatal-perinatal medicine has thus far centered on advancing our understanding of perinatal and postnatal severe acute respiratory syndrome-coronavirus-2 (SARS-CoV-2) transmission, pregnancy outcomes, disease severity among infected newborns, and hospital personnel and equipment shortages. ${ }^{1,2}$

The impact of SARs-CoV-2 on the risk of preterm birth is unknown, though maternal SARS-CoV-2 infection and related complications have influenced delivery decision making received

July 20, 2020

accepted

July 27, 2020

published online

September 10, 2020
DOI https://doi.org/

10.1055/s-0040-1715839.

ISSN 0735-1631.
Copyright $\odot 2020$ by Thieme Medical Publishers, Inc., 333 Seventh Avenue, New York, NY 10001, USA. Tel: +1(212) 760-0888.
License terms

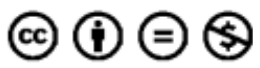


for some patients. ${ }^{3,4}$ Current data suggest that vertical transmission of SARS-CoV-2 may occur, but the direct impact of maternal, fetal, or neonatal SARs-CoV-2 infection on neonatal outcomes is unknown. ${ }^{5-8}$ The downstream effects of the COVID-19 pandemic have included hospital and outpatient clinic policy changes and restricted presence of parents at the bedside, resource and services access challenges for children with special health care needs, and financial, employment, and housing losses for families.

The COVID-19 pandemic is affecting care for high-risk newborns in considerable ways that will likely be sustained beyond the initial pandemic response. These novel challenges present an urgent imperative to understand how COVID-19 impacts parent, family, and infant outcomes. Here, we highlight three areas that warrant targeted attention: inpatient care, outpatient care, and parent psychosocial distress.

\section{Inpatient Care: Visitation Policies, Developmental Care, and Communication Practices}

Many obstetrical and NICU wards have changed visitation processes to mitigate the spread of COVID-19. Some obstetrical units have limited visitors at the time of birth, requiring expectant parents to make choices between partners, doulas, extended family members, and other sources of support.

Many NICUs have also instituted visitation policies (for example, limiting visitors to one per infant). Although such policies are evolving, data obtained from respondent attendees in an ongoing series of COVID-19 webinars, developed by the California Perinatal Quality Care Collaborative (CPQCC), ${ }^{9}$ reveal that nearly all responding California NICUs have changed their family visitor policies, with almost half requiring one family member to be designated as the single visitor allowed for the entire hospitalization.

Parent-driven interventions have a positive impact on infant and parent outcomes. Infants who experience early skin-to-skin contact experience less pain, have improved neurodevelopmental outcomes and growth, and experience less physiologic instability. ${ }^{10-16}$ Parent engagement in infant clinical care improves parent mental health outcomes ${ }^{11,16-18}$ including symptoms of anxiety and depression. Existing data suggest that parents who participate in clinical care feel more competent, bonded with their infant, and prepared for life at home. ${ }^{19-21}$ Changes in visitation policies and care delivery may have a host of downstream consequences such as decreased parent presence at the bedside, decreased engagement in clinical care, and decreased readiness for home.

Decreased parent presence at the bedside has changed the ways in which teams can communicate with families. Daily updates and discussion of major changes to care may occur virtually or by phone. Family conferences, which are often an opportunity for parents to interface with multiple care team members at once, may occur less frequently or be transitioned to a virtual format. Many family conferences typically include team members with expertise and training to provide immediate emotional support to parents in distress. It is unclear if these services are as accessible or effective in a virtual format. In situations where only one family member can be present at an infant's bedside at a time, the family member may need to relay medical information to other loved ones. Existing data suggest that parents may feel burdened by the responsibility of translating medical information to their partner or other family members. ${ }^{22}$

Although not equivalent to bedside presence, one potential adaptation to increase parent participation amidst visitation restrictions is using technology to facilitate virtual participation of parents in rounds, major conversations with the team, and care at the bedside. The degree to which NICUs have implemented these types of programs is unclear. Of CPQCC survey participants, over one-third responded with concerns that technology to accommodate parents' virtual presence was not available or significantly limited. ${ }^{9}$ Parents' access to devices at home was likely also variable and rapid deployment of virtual health care delivery has the potential to exacerbate existing inequity. How parents participate in, engage with, and perceive virtual communication with their infant's care team is unknown.

Changes to parent participation in clinical care and parent presence at the bedside may be particularly relevant as patients and families transition to home. Discharge teaching typically requires in-person education of all caregivers who may be caring for the child. While some elements of discharge teaching may be amenable to virtual instruction, others require hands-on manipulation of equipment or medication. Visitor restrictions may make it challenging for all infant caregivers to receive in-person instruction. Ongoing work should evaluate whether such changes influence length of stay, parent confidence, and parent self-efficacy. ${ }^{23-25}$ These changes present an opportunity to introduce and study the impact of online education resources. ${ }^{26}$

\section{Outpatient Care: High-Risk Infant Follow-up and Early Intervention Programs}

Changes to care delivery are not limited to the inpatient setting. Many outpatient pediatric clinics have embraced telemedicine to deliver care by phone or video-assisted communication; however, access to and implementation of telemedicine is highly variable. These changes have been implemented widely across a broad range of disciplines critical to the care of highrisk infants, including neurodevelopmental follow-up, pediatric specialty, and primary care clinics. This practice change is reflected in - Fig. 1, which summarizes the transition from inperson to a mix of in-person, telephone, and video visits at Duke Children's General Pediatrics and Pediatric Subspecialty Outpatient Clinics.

Access to telehealth infrastructure and appointments likely varies across regions and centers, for example, between large urban centers, suburban communities, and rural areas. The burden of decreased availability of in-person services is likely to fall disproportionally on children with complex health care needs, who interface with the health care system frequently across multiple clinics and whose medical needs may be less amenable to virtual 


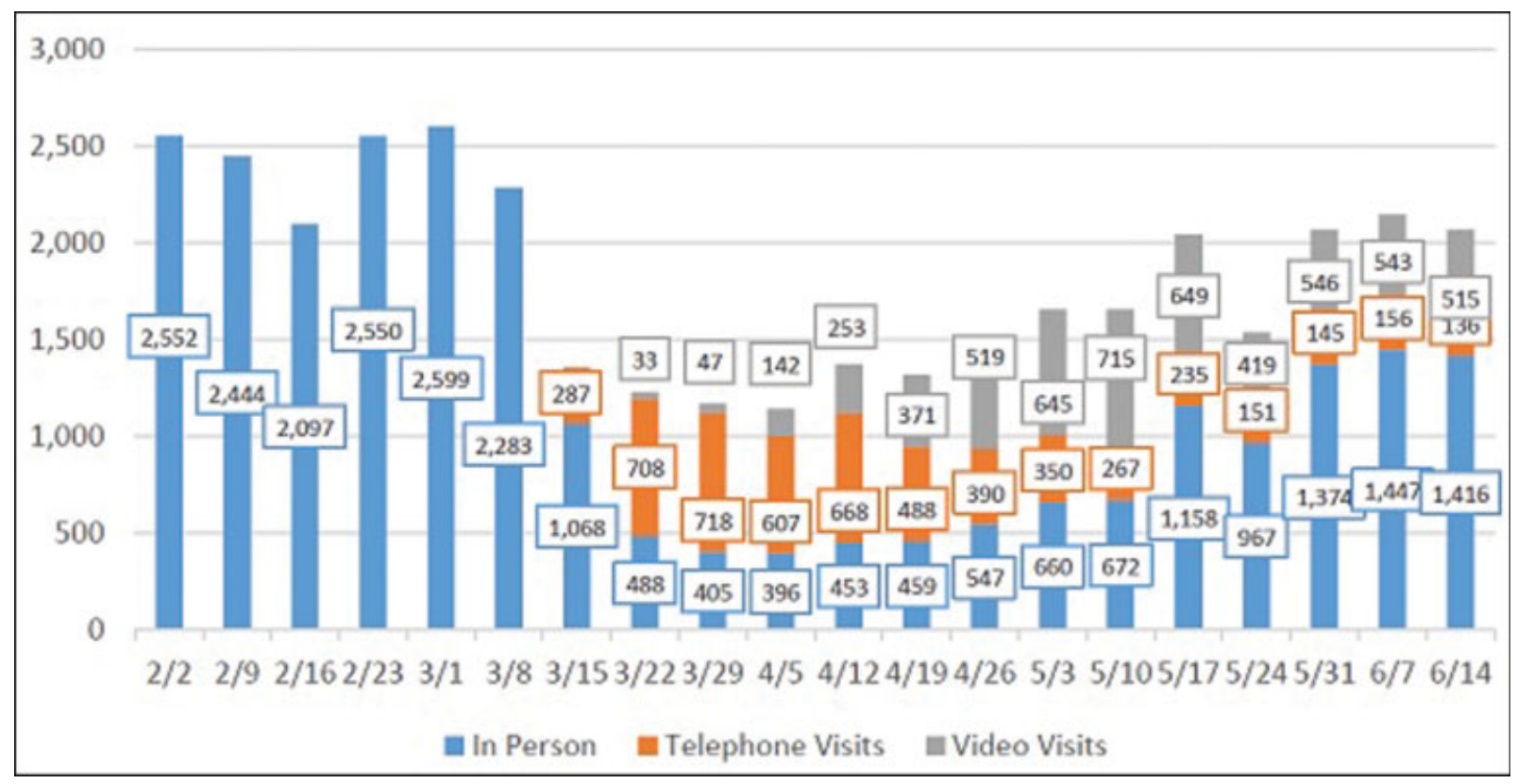

Fig. 1 In person, telephone, and video outpatient arrived visits within Duke Pediatrics.

management. ${ }^{27}$ Children with a history of preterm birth are more likely to require rehabilitation therapy services after discharge. ${ }^{28}$ Early intervention programs improve infant motor and cognitive outcomes. ${ }^{29}$ While some stages of the early intervention process may be amenable to virtual delivery, others benefit from or require face-to-face contact. Engaging with young patients and those with cognitive impairment may be particularly challenging in a virtual setting.

Clinics and parents have been required to weigh in real time in which visits are "essential" and whether to defer care for elective procedures. It is unknown whether decreased inperson visits, including routine well-child care, will result in delayed presentations of illness, decreased immunization rates, or increased morbidity. High-risk infant follow-up is central to the longitudinal care of infants' discharged from the NICU and is recommended by the American Academy of Pediatrics and other expert groups. ${ }^{30,31}$ These programs provide an interprofessional, multidisciplinary approach to the care of high-risk infants that facilitates early identification of neurodevelopmental impairment and timely referral to needed services. ${ }^{32,33}$ Attendance in high-risk infant follow-up clinics that support early intervention services improve infants' neurodevelopmental outcomes ${ }^{34,35}$ and serve as touch points for clinical and research programs. Recent initiatives to integrate standardized motor assessments into high-risk infant follow-up assessments have resulted in shortened time to the diagnosis of cerebral palsy. ${ }^{36}$ Importantly, access to highrisk infant follow-up is not uniform; a large, population-based cohort of extremely low birth weight infants demonstrated an association between socioeconomic factors and attendance in high-risk infant follow-up. ${ }^{37}$

Programs that offer enhanced support around the transition from the NICU to home can decrease infant rehospitalization rates and overall health care costs. ${ }^{38,39}$ These programs may have added benefit during the COVID-19 pandemic, when parents may have less time at the bedside to prepare for life at home. The value of comprehensive medical home programs, which often include increased access to NICU clinicians, should be studied in the setting of decreased in-person access to specialty providers. Within Duke Neonatology's comprehensive medical home program, a rapid transition to video telehealth visits maintained a clinic schedule of approximately $75 \%$ in the early months of the COVID-19 outbreak ( - Fig. 2). This group, which provides parents with around-the-clock pager access to providers in NICU follow-up clinic, also saw a dramatic increase in pager activity during the early stages of the crisis from concerned parents hoping to obtain medical advice without going to urgent care centers.

The COVID-19 pandemic has highlighted existing racial and social disparities in health outcomes. Many fear that the rapid and broad scale implementation of telemedicine in response to COVID-19 may widen disparities in access to health care for vulnerable populations who may have limited access to technology or limited English proficiency. ${ }^{40}$ Up to $25 \%$ of the population has limited digital literacy skills or access to appropriate internet bandwidth to allow participation in a video-enabled telemedicine visit. ${ }^{41,42}$ Nouri and colleagues recommend that hospitals proactively evaluate their telemedicine system to identify and eliminate inherent barriers to access. ${ }^{40}$

Increased use of telehealth services, in both the inpatient and outpatient setting, has the potential to benefit many infants and families, especially those burdened by challenges with transportation, childcare, and chronic medical needs. The rapid uptake of such services in the setting of COVID-19 provides an opportunity to understand how to deploy telemedicine services responsibly and sustainably beyond the COVID era. Meeting goals of perceived patient experience 


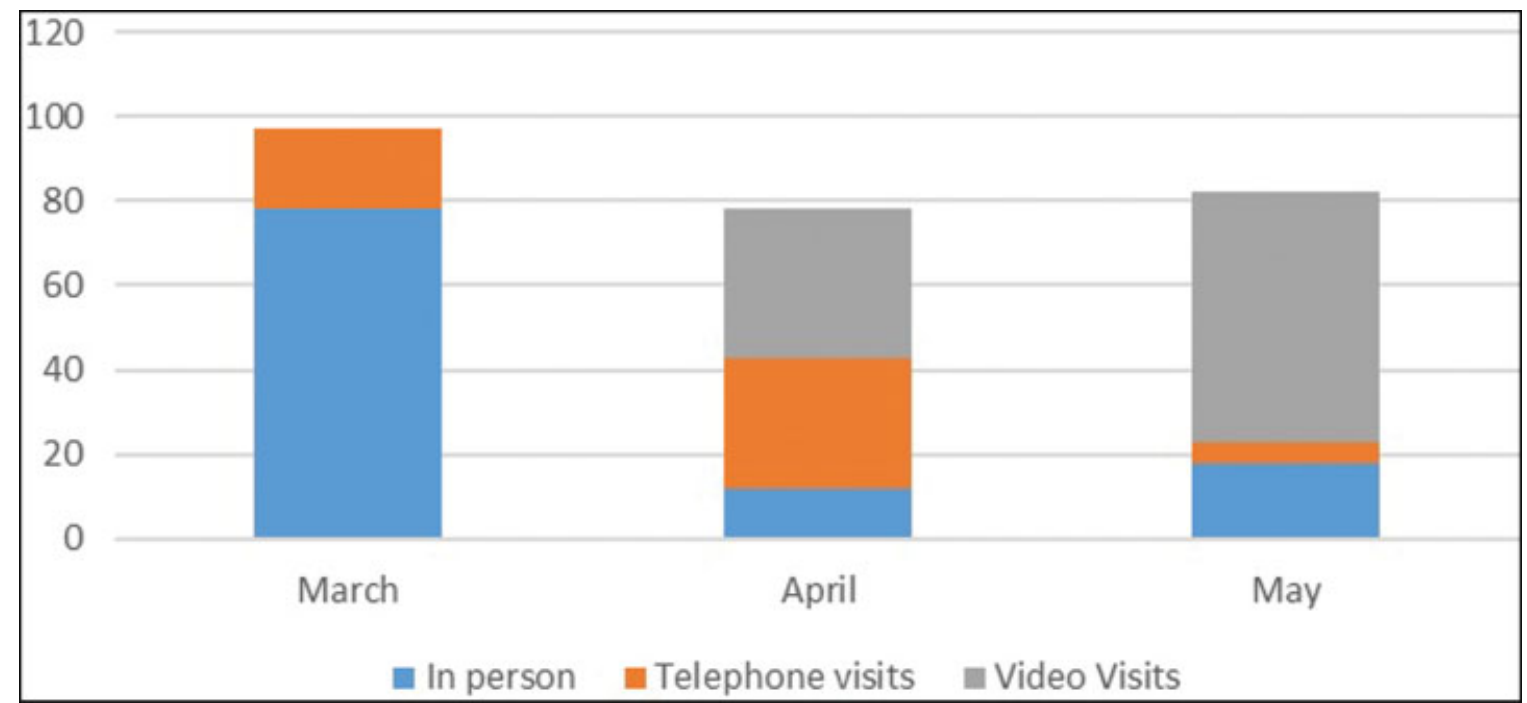

Fig. 2 Outpatient arrived visits for Duke Division of Neonatology.

metrics, along with potential institutional financial benefits, may result in broad telehealth deployment without evidence-based understanding of risks and benefits.

\section{Parent Psychosocial Distress: Mental Health, Social Support, and Financial Toxicity}

In even the most routine of times, the NICU is a stress- and anxiety-provoking place for parents. For parents of children born extremely preterm, the NICU is the location of what is likely one of the most traumatic experiences in the life of their family. ${ }^{23}$ At baseline, parents of babies in the NICU are at significantly increased risk of depression, anxiety, and trauma, which can persist for long periods after discharge. ${ }^{43}$ As many as two in three mothers of preterm infants in the NICU have depressive symptoms, and up to half have symptoms of anxiety. Approximately one in four parents will experience symptoms of posttraumatic stress. ${ }^{44-47}$ Neonatal clinical factors alone are not sufficient to predict which parents will experience mental health challenges; Shaw et $\mathrm{al}^{47}$ found no relationship between maternal symptoms of posttraumatic stress in the NICU and a wide range of neonatal clinical variables. These data argue for the importance of routine mental health screening in parents of premature infants.

Peer support programs can mitigate mental health challenges experienced by parents. ${ }^{48-53}$ Many face-to-face peer support programs rely on volunteer support and include parent gatherings; most NICUs have suspended these activities in the setting of COVID-19 restrictions. This void highlights the potential role of virtual peer support programs; clinicians should actively connect parents to relevant organizations.

Parental symptoms of anxiety, depression, and posttraumatic stress can extend far beyond the NICU stay and can have profound impacts on relationships, communication, and parenting. High-stress and trauma symptoms among mothers in the NICU are associated with dysfunctional coping and increased perception of child vulnerability later in life. ${ }^{44,54,55}$ Existing data additionally suggest that poor parent mental health outcomes are associated with worse childhood developmental outcomes including cognitive, behavioral, and fine motor challenges. ${ }^{56,57}$

The COVID-19 pandemic crisis is likely to have a substantially additive effect on the stressors already felt by our patients' families in the NICU and in the community. Mental health challenges are not isolated to parents in the home and may affect siblings and other caregivers. Survey data from more than 2,300 school-aged students confined to home during the height of the crisis in China's Hubei province revealed that nearly one in four had symptoms of depression, and one in five had symptoms of anxiety. ${ }^{58}$ Previous epidemics, including SARS and H1N1, resulted in increased rates of depressive and posttraumatic stress symptoms, and some studies suggest increased risk of substance dependence and abuse. ${ }^{59,60}$

Families may also be facing broader challenges that undermine their ability to care for a high-risk infant. Family financial constraints and resource limitations may result directly in housing insecurity, food insecurity, and the inability to obtain social supports. The disruption in the social support structure due to the need for social distancing may increase feelings of isolation and depressive symptoms in caregivers. Obtaining safe childcare may be challenging; many parents may be unable to rely on family and friends due to social distancing constraints. Financial distress may amplify parent mental health challenges. Data from previous pandemics suggest that financial loss is a risk factor for symptoms of depression, anxiety, and posttraumatic stress. $^{61-63}$ Fortunately, several evidence-based treatments effectively address the psychological distress experienced by parents of preterm infants. ${ }^{24}$

The COVID-19 pandemic has precipitated an abrupt but successful transition to telehealth services in the mental health field. For those with access to technology, telehealth delivery of mental health services may relieve barriers to accessing care due to travel challenges, time constraints, or other logistical concerns. For others, lack of access to 
adequate technology may limit their ability to receive necessary care at a time of heightened risk.

\section{Conclusion}

The COVID-19 pandemic and necessary mitigation strategies have introduced significant changes to care delivery for highrisk infants and their families. These changes provide an opportunity to identify and implement novel strategies to provide family-centered care to support families during COVID-19 and beyond.

Funding

M.E.L. is supported by the National Institutes of Neurological Disorders and Stroke (K23NS116453).

\section{Conflict of Interest}

None declared.

\section{References}

1 National registry for surveillance and epidemiology of perinatal COVID-19 infection. Available at: https://services.aap.org/globalassets/sonpm/sonpmdatadictionaryregistry.pdf. Accessed August 3, 2020

2 Mullins E. A global registry of women affected by COVID-19 in pregnancy and their babies, to guide treatment and prevention. London, UK: Imperial College Healthcare NHS Trust; 2020

3 Della Gatta AN, Rizzo R, Pilu G, Simonazzi G. Coronavirus disease 2019 during pregnancy: a systematic review of reported cases. Am J Obstet Gynecol 2020;223(01):36-41

4 Di Mascio D, Khalil A, Saccone G, et al. Outcome of Coronavirus spectrum infections (SARS, MERS, COVID-19) during pregnancy: a systematic review and meta-analysis. Am J Obstet Gynecol MFM 2020;2(02):100107

5 Chen H, Guo J, Wang C, et al. Clinical characteristics and intrauterine vertical transmission potential of COVID-19 infection in nine pregnant women: a retrospective review of medical records. Lancet 2020;395(10226):809-815

6 Lamouroux A, Attie-Bitach T, Martinovic J, Leruez-Ville M, Ville Y. Evidence for and against vertical transmission for SARS-CoV-2 (COVID-19). Am J Obstet Gynecol 2020;223(01):91.e1-91.e4

7 Karimi-Zarchi M, Neamatzadeh H, Dastgheib SA, et al. Vertical transmission of coronavirus disease 19 (COVID-19) from infected pregnant mothers to neonates: a review. Fetal Pediatr Pathol 2020;39(03):246-250

8 Vivanti AJ, Vauloup-Fellous C, Prevot S, et al. Transplacental transmission of SARS-CoV-2 infection. Nat Commun 2020;11(01):3572

9 CPQCC/CMQCC. COVID-19 resources for maternal and infant health. CA Perinatal Programs. . Available at: https://www.caperinatalprograms.org/Accessed August 3, 2020

10 Boundy EO, Dastjerdi R, Spiegelman D, et al. Kangaroo mother care and neonatal outcomes: a meta-analysis. Pediatrics 2016; 137(01):

11 Holditch-Davis D, White-Traut RC, Levy JA, O'Shea TM, Geraldo V, David RJ. Maternally administered interventions for preterm infants in the NICU: effects on maternal psychological distress and motherinfant relationship. Infant Behav Dev 2014;37(04):695-710

12 Johnston C, Campbell-Yeo M, Disher T, et al. Skin-to-skin care for procedural pain in neonates. Cochrane Database Syst Rev 2017;2: CD008435

13 Karimi FZ, Sadeghi R, Maleki-Saghooni N, Khadivzadeh T. The effect of mother-infant skin to skin contact on success and duration of first breastfeeding: a systematic review and metaanalysis. Taiwan J Obstet Gynecol 2019;58(01):1-9
14 Lumbanraja SN. Influence of maternal factors on the successful outcome of kangaroo mother care in low birth-weight infants: A randomized controlled trial. J Neonatal Perinatal Med 2016;9 (04):385-392

15 Nyqvist KH, Anderson GC, Bergman N, et al; Expert Group of the International Network on Kangaroo Mother Care. State of the art and recommendations. Kangaroo mother care: application in a high-tech environmentActa Paediatr 2010;99(06):812-819

16 Sweeney S, Rothstein R, Visintainer P, Rothstein R, Singh R. Impact of kangaroo care on parental anxiety level and parenting skills for preterm infants in the neonatal intensive care unit. J Neonatal Nurs 2017;23(03):151-158

17 Athanasopoulou E, Fox JRE. Effects of kangaroo mother care on maternal mood and interaction patterns between parents and their preterm, low birth weight infants: a systematic review. Infant Ment Health J 2014;35(03):245-262

18 Bera A, Ghosh J, Singh AK, Hazra A, Mukherjee S, Mukherjee R. Effect of kangaroo mother care on growth and development of low birthweight babies up to 12 months of age: a controlled clinical trial. Acta Paediatr 2014;103(06):643-650

19 Franck LS, O'Brien K. The evolution of family-centered care: From supporting parent-delivered interventions to a model of family integrated care. Birth Defects Res 2019;111(15):1044-1059

20 Benzies KM, Magill-Evans JE, Hayden KA, Ballantyne M. Key components of early intervention programs for preterm infants and their parents: a systematic review and meta-analysis. BMC Pregnancy Childbirth 2013;13(01, Suppl 1):S10

21 Evans T, Whittingham K, Sanders M, Colditz P, Boyd RN. Are parenting interventions effective in improving the relationship between mothers and their preterm infants? Infant Behav Dev 2014;37(02):131-154

22 Lemmon ME, Donohue PK, Parkinson C, Northington FJ, Boss RD. Communication challenges in neonatal encephalopathy. Pediatrics 2016;138(03):e20161234

23 Sabnis A, Fojo S, Nayak SS, Lopez E, Tarn DM, Zeltzer L. Reducing parental trauma and stress in neonatal intensive care: systematic review and meta-analysis of hospital interventions. J Perinatol 2019;39(03):375-386

24 Shaw RJ, John NSt., Lilo E, et al. Prevention of traumatic stress in mothers of preterms: 6-month outcomes. Pediatrics 2014;134 (02):e481-e488

25 Horwitz SM, Leibovitz A, Lilo E, et al. Does an intervention to reduce maternal anxiety, depression and trauma also improve mothers' perceptions of their preterm infants' vulnerability? Infant Ment Health J 2015;36(01):42-52

26 MOD. NICU Family Online Education Series - COVID-19. March of Dimes. Available at: https://www.marchofdimes.org/nicufamilysupport/covid-19-online-nicu-family-education-series.aspxAccessed August 3, 2020

27 Ernsting C, Stühmann LM, Dombrowski SU, Voigt-Antons JN, Kuhlmey A, Gellert P. Associations of health app use and perceived effectiveness in people with cardiovascular diseases and diabetes: population-based survey. JMIR Mhealth Uhealth 2019;7(03): e12179

28 Clements KM, Barfield WD, Ayadi MF, Wilber N. Preterm birthassociated cost of early intervention services: an analysis by gestational age. Pediatrics 2007;119(04):e866-e874

29 Spittle A, Orton J, Anderson PJ, Boyd R, Doyle LW. Early developmental intervention programmes provided post hospital discharge to prevent motor and cognitive impairment in preterm infants. Cochrane Database Syst Rev 2015;(11):CD005495

30 American Academy of Pediatrics Committee on Fetus and Newborn. Hospital discharge of the high-risk neonate. Pediatrics 2008;122(05):1119-1126

31 Wang CJ, McGlynn EA, Brook RH, et al. Quality-of-care indicators for the neurodevelopmental follow-up of very low birth weight children: results of an expert panel process. Pediatrics 2006;117 (06):2080-2092 
32 Kuppala VS, Tabangin M, Haberman B, Steichen J, Yolton K. Current state of high-risk infant follow-up care in the United States: results of a national survey of academic follow-up programs. J Perinatol 2012;32(04):293-298

33 Greene M, Patra K. Part C early intervention utilization in preterm infants: opportunity for referral from a NICU follow-up clinic. Res Dev Disabil 2016;53-54:287-295

34 Spittle A, Orton J, Anderson P, Boyd R, Doyle LW. Early developmental intervention programmes post-hospital discharge to prevent motor and cognitive impairments in preterm infants. Cochrane Database Syst Rev 2012;12:CD005495

35 McManus BM, Carle AC, Poehlmann J. Effectiveness of part C early intervention physical, occupational, and speech therapy services for preterm or low birth weight infants in Wisconsin, United States. Acad Pediatr 2012;12(02):96-103

36 Maitre NL, Burton VJ, Duncan AF, et al. Network implementation of guideline for early detection decreases age at cerebral palsy diagnosis. Pediatrics 2020;145(05):e20192126

37 Hintz SR, Gould JB, Bennett MV, et al. Factors associated with successful first high-risk infant clinic visit for very low birth weight infants in California. J Pediatr 2019;210:91-98.e1

38 Vohr B, McGowan E, Keszler L, et al. Impact of a transition home program on rehospitalization rates of preterm infants. J Pediatr 2017;181:86-92.e1

39 Liu Y, McGowan E, Tucker R, Glasgow L, Kluckman M, Vohr B. Transition home plus program reduces medicaid spending and health care use for high-risk infants admitted to the neonatal intensive care unit for 5 or more days. J Pediatr 2018;200:91-97.e3

40 Nouri S, Khoong EC, Lyles CR, Karliner L. Addressing equity in telemedicine for chronic disease management during the COVID19 pandemic. . Available at: https://catalyst.nejm.org/doi/pdf/ 10.1056/CAT.20.0123. Accessed August 3, 2020

41 Pew Research Center. Mobile fact sheet. Available at: http://www. pewinternet.org/fact-sheet/mobile/. Accessed April 6, 2020

42 Pew Research Center. Internet/broadband fact sheet. Available at: http://www.pewinternet.org/fact-sheet/internet-broadband/. Accessed April 2, 2020

43 Feeley N, Zelkowitz P, Cormier C, Charbonneau L, Lacroix A, Papageorgiou A. Posttraumatic stress among mothers of very low birthweight infants at 6 months after discharge from the neonatal intensive care unit. Appl Nurs Res 2011;24(02):114-117

44 Shaw RJ, Bernard RS, Storfer-Isser A, Rhine W, Horwitz SM. Parental coping in the neonatal intensive care unit. J Clin Psychol Med Settings 2013;20(02):135-142

45 Garel M, Dardennes M, Blondel B. Mothers' psychological distress 1 year after very preterm childbirth. Results of the EPIPAGE qualitative study. Child Care Health Dev 2007;33(02):137-143

46 Yildiz PD, Ayers S, Phillips L. The prevalence of posttraumatic stress disorder in pregnancy and after birth: a systematic review and meta-analysis. J Affect Disord 2017;208:634-645

47 Shaw RJ, Deblois T, Ikuta L, Ginzburg K, Fleisher B, Koopman C. Acute stress disorder among parents of infants in the neonatal intensive care nursery. Psychosomatics 2006;47(03):206-212
48 Hall SL, Ryan DJ, Beatty J, Grubbs L. Recommendations for peer-topeer support for NICU parents. J Perinatol 2015;35(Suppl 1): S9-S13

49 Kerr SM, McIntosh JB. Coping when a child has a disability: exploring the impact of parent-to-parent support. Child Care Health Dev 2000;26(04):309-322

50 Jarrett MH. Parent partners: a parent-to-parent support program in the NICU. Part II: Program implementation. Pediatr Nurs 1996; 22(02):142-144, 149

51 Nearing GB, Salas AA, Granado-Villar D, Chandler BD, Soliz A. Psychosocial parental support programs and short-term clinical outcomes in extremely low-birth-weight infants. J Matern Fetal Neonatal Med 2012;25(01):89-93

52 Lindsay JK, Roman L, DeWys M, Eager M, Levick J, Quinn M. Creative caring in the NICU: parent-to-parent support. Neonatal Netw 1993;12(04):37-44

53 Dennis CL, Hodnett E, Kenton L, et al. Effect of peer support on prevention of postnatal depression among high risk women: multisite randomised controlled trial. BMJ 2009;338:a3064

54 Ahlund S, Clarke P, Hill J, Thalange NKS. Post-traumatic stress symptoms in mothers of very low birth weight infants 2-3 years post-partum. Arch Women Ment Health 2009;12(04): 261-264

55 Horwitz SM, Storfer-Isser A, Kerker BD, et al. A model for the development of mothers' perceived vulnerability of preterm infants. J Dev Behav Pediatr 2015;36(05):371-380

56 Greene MM, Rossman B, Meier P, Patra K. Elevated maternal anxiety in the NICU predicts worse fine motor outcome in VLBW infants. Early Hum Dev 2018;116:33-39

57 Zelkowitz P, Na S, Wang T, Bardin C, Papageorgiou A. Early maternal anxiety predicts cognitive and behavioural outcomes of VLBW children at 24 months corrected age. Acta Paediatr 2011; 100(05):700-704

58 Xie X, Xue Q, Zhou Y, et al. Mental health status among children in home confinement during the coronavirus disease 2019 outbreak in Hubei Province, China. JAMA Pediatr 2020 (e-pub ahead of print). Doi: 10.1001/jamapediatrics.2020.1619

59 Brooks SK, Webster RK, Smith LE, et al. The psychological impact of quarantine and how to reduce it: rapid review of the evidence. Lancet 2020;395(10227):912-920

60 Wu P, Liu X, Fang Y, et al. Alcohol abuse/dependence symptoms among hospital employees exposed to a SARS outbreak. Alcohol Alcohol 2008;43(06):706-712

61 Mihashi M, Otsubo Y, Yinjuan X, Nagatomi K, Hoshiko M, Ishitake T. Predictive factors of psychological disorder development during recovery following SARS outbreak. Health Psychol 2009;28 (01):91-100

62 Jeong H, Yim HW, Song YJ, et al. Mental health status of people isolated due to middle east respiratory syndrome. Epidemiol Health 2016;38:e2016048

63 Hawryluck L, Gold WL, Robinson S, Pogorski S, Galea S, Styra R. SARS control and psychological effects of quarantine, Toronto, Canada. Emerg Infect Dis 2004;10(07):1206-1212 